\title{
BMJ Open Prevalence of tobacco use and perceptions of student health professionals about cessation training: results from Global Health Professions Students Survey
}

Chandrashekhar T Sreeramareddy, ${ }^{1}$ N Ramakrishnareddy, ${ }^{2}$ Mahbubur Rahman, ${ }^{3}$ Imtiyaz Ali Mir ${ }^{4}$

To cite: Sreeramareddy CT, Ramakrishnareddy $\mathrm{N}$, Rahman M, et al. Prevalence of tobacco use and perceptions of student health professionals about cessation training: results from Global Health Professions Students Survey. BMJ Open 2018;8:e017477. doi:10.1136/ bmjopen-2017-017477

- Prepublication history and additional material for this paper are available online. To view these files, please visit the journal online (http://dx.doi. org/10.1136/bmjopen-2017017477).

Received 25 April 2017

Revised 1 April 2018

Accepted 18 April 2018

Check for updates

${ }^{1}$ Department of Community Medicine, International Medical University, Bukit Jalil, Malaysia ${ }^{2}$ Department of Community Medicine, Bangalore Medical College and Research Institute, Fort, Bangalore, India ${ }^{3}$ Disease Control \& Research (IEDCR), Institute of

Epidemiology, Dhaka, Mohakali, Bangladesh

${ }^{4}$ Physiotherapy, Faculty of Medicine and Health Sciences, Universiti Tunku Abdul Rahman, Bandar Sungai Long, Selangor, Malaysia

Correspondence to Dr Chandrashekhar

T Sreeramareddy;

chandrashekharats@yahoo.com

\section{ABSTRACT}

Introduction Health professionals play an important role in providing advice to their patients about tobacco prevention and cessation. Health professionals who use tobacco may be deterred from providing cessation advice and counselling to their patients. We aimed to provide prevalence estimates of tobacco use among student health professionals and describe their attitudes towards tobacco cessation training.

Methods Country-wise aggregate data from the Global Health Professions Student Survey on 'current cigarette smoking' (smoking cigarettes on 1 or more days during the past 30 days), and 'current use of tobacco products other than cigarettes' (chewing tobacco, snuff, bidis, cigars or pipes, 1 or more days during the past 30 days) were analysed. For each WHO region, we estimated mean prevalence rates of tobacco use weighted by the population of the sampling frame and aggregate proportions for 'health professionals' role' and 'cessation training' indicators using 'metaprop' command on Stata V.11.

Results A total of 107527 student health professionals participated in 236 surveys done in four health profession disciplines spanning 70 countries with response rates ranging from $40 \%$ to $100 \%$. Overall, prevalence of smoking was highest in European countries $(20 \%$ medical and $40 \%$ dental students) and the Americas (13\% pharmacy to $23 \%$ dental students). Other tobacco use was higher in eastern Mediterranean (10\%-23\%) and European countries $(7 \%-13 \%)$. In most WHO regions, $\geq 70 \%$ of the students agreed that health professionals are role models, and have a role in advising about smoking cessation to their patients and the public. Only $\leq 33 \%$ of all student health professionals in most WHO regions (except 80\% dental students in the Eastern Mediterranean region) had received formal training on smoking cessation approaches and $\geq 80 \%$ of all students agreed that they should receive formal cessation training.

Conclusions Tobacco control should take place together with medical educators to discourage tobacco use among student health professionals and implement an integrated smoking cessation training into health professions' curricula.

\section{Strengths and limitations of this study}

- We provide an up-to-date comprehensive report of all countries surveyed in the Global Health Professions Student Survey (GHPSS).

- Standardised survey protocols and questionnaires of GHPSS enabled cross-country comparison and calculate estimates for WHO regions.

- Our regional estimates were non-representative and inconsistent due to limited coverage of countries and small survey samples in some WHO regions.

- GHPSS surveyed students in medicine, dentistry, nursing and pharmacy only, whereas health professions such as optometry, physiotherapy, and so on, also have a role in tobacco cessation.

\section{INTRODUCTION}

Globally, tobacco use is a major preventable cause of premature mortality and morbidity. ${ }^{1}$ Tobacco smoking inclusive of secondhand smoke (SHS) is a leading risk factor attributable to $6 \%$ of global disability-adjusted life years. $^{2}$ An estimated 967 million smokers are living in 187 countries and this number is expected to increase with the growing population $^{3}$ and worsening tobacco epidemic in developing countries. ${ }^{4}$ The WHO Framework Convention on Tobacco Control (FCTC) recommends that the global tobacco epidemic be monitored through population-based surveys conducted through the Global Tobacco Surveillance System (GTSS) among adults, youth, school personnel and student health professionals. ${ }^{5}$

WHO FCTC underscores the importance of the role played by doctors, dentists, nurses, pharmacists, optometrists, and so on, in cessation and prevention of tobacco use by providing brief counselling or even simple advice. $^{67}$ Cessation training for student 
health professionals may be potentially a very significant contribution towards tobacco control efforts. ${ }^{8}$ However, health professionals' smoking habit may deter them from providing cessation advise and counselling to their patients because they cannot persuade patients to quit if they were smoking themselves. ${ }^{9}{ }^{10}$ Student health professionals have inadequate knowledge about smoking-related diseases and receive very little or no training on tobacco cessation techniques. ${ }^{11} 12$

Training student health professionals in smoking cessation could potentially have an impact on their future professional practice by helping patients who smoke quit either by interviewing, simple advice or referrals to cessation clinics. ${ }^{13-15}$ In many medical schools in AfroAsian developing countries, tobacco cessation training is not provided at all or given non-systematically. ${ }^{16}$ Medical students usually ask patients their smoking history during clinical rotations but they seldom ask or advise about cessation. ${ }^{17}$ Hence, there is continued debate on introducing tobacco cessation training into health professions' curricula. ${ }^{18-20}$ The Global Health Professions Student Survey (GHPSS) ${ }^{21}$ has resulted in separate publications on country-specific estimates for medical, ${ }^{22}$ dental, ${ }^{23}$ nursing ${ }^{24}$ and pharmacy ${ }^{25}$ disciplines. Yet, a comprehensive report is unavailable on all WHO regions and all four disciplines. Such information about the prevalence of tobacco use and the student health professionals' attitude towards cessation is important for medical educators and tobacco control policy makers. ${ }^{26}{ }^{27}$ Using aggregated GHPSS data, we aimed to provide updated global, regional and country-level estimates on prevalence of tobacco use among medical, dental, nursing and pharmacy students and describe their attitudes towards tobacco cessation training.

\section{METHODS}

\section{Survey design}

The WHO, the Centers for Disease Control (CDC) and the Canadian Public Health Association have standardised the study procedures for administering a validated core GHPSS questionnaire. ${ }^{28}$ The GHPSS is a school-based, cross-sectional survey administered to third-year students pursuing advanced degrees in medicine, dentistry, nursing and pharmacy. In each country, trained research coordinators ensured that standard survey protocols were implemented. The GHPSS used a two-stage sampling design, based on probability proportional to the enrolment size of third-year students in health professions' schools in each country. The GHPSS was conducted as a census of schools and students in most locations and disciplines. In each country, the number of participants surveyed was different since the number of schools and students varied. ${ }^{29}$

\section{Data collection}

The GHPSS used a validated anonymous, self-administered questionnaire covering demographics, cigarette smoking and use of other tobacco products, exposure to SHS, desire to quit smoking and training received to provide patient counselling and on cessation techniques. The collaborators adapted a core questionnaire by adding questions about local forms of tobacco consumed in each country. Where appropriate the core questionnaire in English was translated into the native language of the country. Native language questionnaires were back-translated to English to check for accuracy and compatibility with the core questionnaire. The survey was conducted in schools during regular lectures and classroom sessions after a briefing session by the research coordinators. The responses were recorded on sheets that could be scanned and converted into data at the CDC. All the surveys followed standardised procedures for selecting the schools, data analyses and processing.

\section{Patient and public involvement}

The GHPSS was carried out considering the needs of the public in terms of competencies to help smokers quit their habits. Patients or the public were not directly involved or participated in the research. Nevertheless, the main results, data sets and core indicators were made available in the public domain.

\section{Ethical considerations}

The GHPSS protocols were approved by the respective WHO regional offices and CDC as per the ethical review procedures for GTSS. Detailed information was verbally provided to all potential participants and informed consent was obtained. Self-administered questionnaires did not ask for any personal identification details.

\section{Statistical analyses}

The GHPSS has created a standard set of variables from the core questions to facilitate cross-country comparisons. 'Current cigarette smoking'was defined as smoking cigarettes on one or more days during the past 30 days. 'Current use of tobacco products other than cigarettes' was defined as using chewing tobacco, snuff, bidis, cigars or pipes (adapted to suit each country) on one or more days during the past 30 days. GHPSS uses SUDAAN software to calculate prevalence estimates and their 95\% CIs. For countries where census was carried out, a finite population correction was applied to adjust for variance in prevalence estimates and also for non-response. For countries where sampling was done, a weighting factor was applied to account for the probability of being sampled in a complex survey design and non-response.

We obtained country-wise aggregate data of GHPSS for 'prevalence of tobacco use' and 'role model and cessation training' from the GTSS website (http://nccd.cdc.gov/ gtssdata/Default/Default.aspx). For each of the four health profession disciplines, we calculated aggregate prevalence estimates and 'health professionals role' and 'cessation training' indicators for the six WHO regions and overall (global). Aggregate prevalence estimates for each of the six WHO regions and each of the four health 
profession disciplines were calculated as means weighted by the population of the sampling frame (national or subnational as appropriate) of the age group (20-30 years) obtained from the International Database of the US Census Bureau (http://www.census.gov/population/ international/data/idb/informationGateway.php). For 'health professionals role' and 'cessation training' indicators, we first obtained raw proportions from the original data sets. Aggregate proportions for each of the six WHO regions and each of the four health profession disciplines were calculated from the raw proportions using 'metaprop' command $^{30}$ using random effects model on Stata/IC (Statacorp, V.11.0, 2007).

\section{RESULTS}

\section{Survey and sample characteristics}

Table 1 shows sample characteristics of all surveys included for the analyses and countries surveyed in the six WHO regions. Data from 236 surveys implemented during 2005-2011 covering four health profession disciplines spanning 70 countries were analysed. The number of countries surveyed varied by disciplines; 70 (medical), 56 (dental), 56 (nursing) and 54 (pharmacy) and total surveys varied by WHO regions for all courses; 17 (WPRO), 25(SEARO \& AFRO), 55 (AMRO), 56 (EMRO) and 58 (EURO) (table 1). A total of 107527 (68 809 female and 37886 male) student health professionals were surveyed, of whom 51914 were in medicine while others were in nursing (26 342), dentistry (14 578) and pharmacy (14 693) courses (table 1). The male-to-female student ratio was highest for nursing (1:4.3) followed by dentistry (1:1.86). Country-wise, discipline-wise and sex-wise samples of students surveyed are shown in the online supplementary web appendix.

\section{Prevalence of current smoking and other tobacco use in WHO regions}

Sex-wise overall prevalence rates of 'current cigarette smoking' and 'current other tobacco use' among students of four health profession disciplines in the six WHO regions are shown in table 2, whereas weighted prevalence rates in all surveyed countries and country-wise prevalence for four disciplines are shown in the online supplementary web appendix. In general, by disciplines 'current cigarette smoking'was higher among dental and pharmacy students whereas overall prevalence in all four disciplines was highest in European countries followed by countries surveyed in the Americas. 'Current cigarette smoking' among female students was higher in European countries and countries in the Americas while both 'current cigarette smoking' and 'current other tobacco use' were lowest in African and South-East Asian countries. Other tobacco use was lower than smoking in the countries of all regions and all disciplines, except for male nursing and male dental students in the Eastern Mediterranean countries, and dental students in European countries where other tobacco use was nearly same as cigarette smoking. Other tobacco use was much higher among male students in countries surveyed in all regions and all disciplines except pharmacy students in the Western Pacific countries.

Cigarette smoking among medical students was highest in European countries (29.2\%), followed by countries in the Americas $(20.3 \%)$ and lowest in African countries $(8.2 \%)$. Male medical students had higher cigarette smoking rates than female students in countries from all regions, but the gap was highest in South-East Asian countries $(18.4 \%$ vs $0.3 \%)$. Among male and female medical students both cigarette smoking and other tobacco use rates were highest in European countries (male 36.0\%$18.9 \%$; female 25.2\%-9.1\%, respectively). However, lowest male and female cigarette smoking rates were seen in African countries (male $12.3 \%$ and female 5.0\%) whereas other tobacco use was lowest in the Western Pacific (male $5.6 \%$ and female $1.4 \%$ ) and African (male $6.2 \%$ and female $2.8 \%$ ) countries.

Cigarette smoking among dental students was highest in European countries (overall 40.2\%; male $47.2 \%$; female $35.2 \%)$ and lowest in African (6.5\%), Western Pacific (male, $11.0 \%$ ) and South-East Asian (female $0.1 \%$ ) countries. The male-to-female gap was highest in South-East Asian countries $(23.4 \%$ vs $0.1 \%)$. Other tobacco use was highest in the Eastern Mediterranean countries for both male $(23.4 \%)$ and female $(8.5 \%)$ students but lowest among male students in the countries in the Western Pacific region $(2.5 \%)$ and female students in the African region $(4.4 \%)$.

Among nursing students, the overall highest cigarette smoking rate was in European countries (28.3\%) and highest other tobacco use rate was in the Eastern Mediterranean countries $(23.8 \%)$. Sex-wise, the cigarette smoking rate was highest in European countries (male $34.3 \%$ and female $27.5 \%$ ), and the lowest prevalence was in African (male 10.2\%) and South-East Asian (female $0.1 \%$ ) countries. Other tobacco use in male and female nursing students was highest in Eastern Mediterranean (27.2\%) and European (6.8\%) countries, respectively.

Among pharmacy students, the overall smoking prevalence was $38.4 \%$ in European countries and about $12 \%$ in the countries surveyed in the Eastern Mediterranean region, South-East Asia and the Americas. Among pharmacy students, sex-wise smoking rates were also higher in European countries $(55.8 \%$ male and $34.2 \%$ female) and lowest in African (male 10.8\%) and SouthEast Asian (female 1.1\%) countries. Prevalence of other tobacco use was highest in European countries (male $28.9 \%$ ) and the Americas (female 10.3\%) whereas prevalence was the lowest in countries in the Western Pacific (male, $2.0 \%$ ) and African (female, $0.6 \%$ ) regions.

\section{Perceptions about health professionals' roles and their cessation training}

Tables 3 and 4 present 'health professionals role' and 'cessation training' indicators for the six WHO regions by sex, and the online supplementary web appendix presents data for overall pooled average for all surveyed countries, 
Table 1 Characteristics of participating countries, student health professionals by male and female and WHO regions

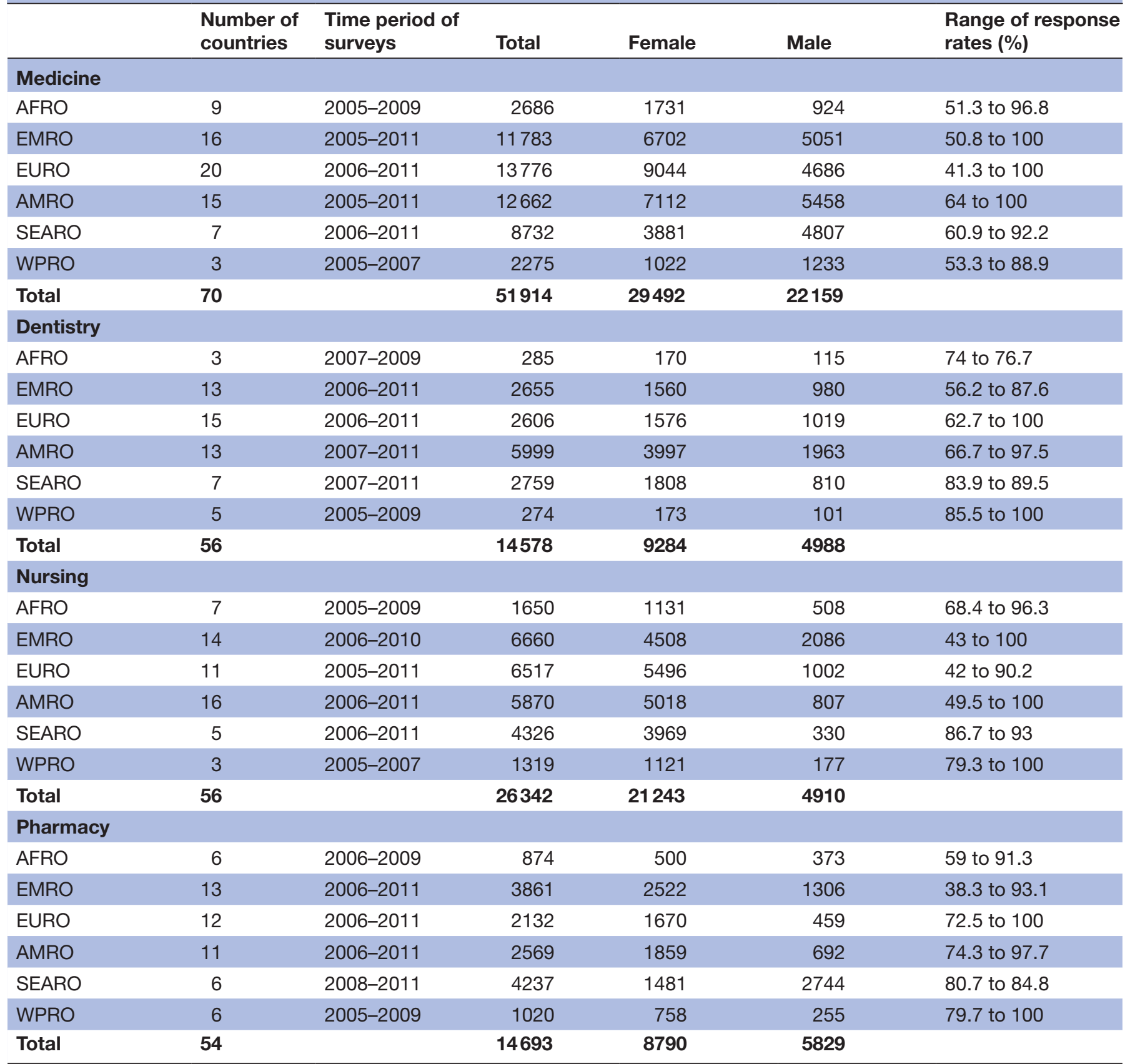

The list of countries in each region is given below as per WHO regional offices. The number of countries surveyed and year of survey varied for each health profession discipline and WHO regions.

AFRO-Algeria, Côte d'Ivoire, Ghana, Kenya, Mozambique, Niger, Senegal, Uganda, Zambia.

EMRO-Bahrain, Egypt, Gaza Strip West Bank, Islamic Republic of Iran, Iraq, Jordan, Lebanon, Libyan Arab Jamahiriya, Morocco, Oman,

Pakistan, Saudi Arabia, Somalia, Sudan, Syrian Arab Republic, Tunisia, Yemen.

EURO- Albania, Armenia, Bosnia and Herzegovina, Bulgaria, Croatia, Czech Republic, Georgia, Greece, Italy, Kyrgyzstan, Latvia, Lithuania, Macedonia, Republic of Moldova, Poland, Russian Federation, Serbia, Slovakia, Slovenia, Spain, Turkey, Ukraine.

SEARO-Bangladesh, India, Indonesia, Myanmar, Nepal, Sri Lanka, Thailand.

AMRO-Argentina, Barbados, Plurinational State of Bolivia, Brazil, Belize, Chile, Costa Rica,Cuba, Havana, Guatemala, Guyana, Jamaica, Mexico, Panama, Paraguay, Peru, Saint Lucia Suriname, Trinidad and Tobago, Uruguay, Bolivarian Republic of Venezuela. WPRO-

Cambodia, Fiji, Lao People's Democratic Republic, Mongolia, Papua New Guinea, Philippines, South Korea, Vietnam.

and each participating country for all four disciplines. About $70 \%-90 \%$ of all student health professionals recognised that they are role models for their patients and the public, except for medical and pharmacy students in the European countries $(65.9 \%$ and $65.1 \%$, respectively); dental (14.4\%) and pharmacy (51.5\%) students in the Western Pacific and pharmacy students in African countries $(67.3 \%)$. About $78 \%-97 \%$ of all student health professionals surveyed in countries of all regions thought that they have a role in giving advice or 


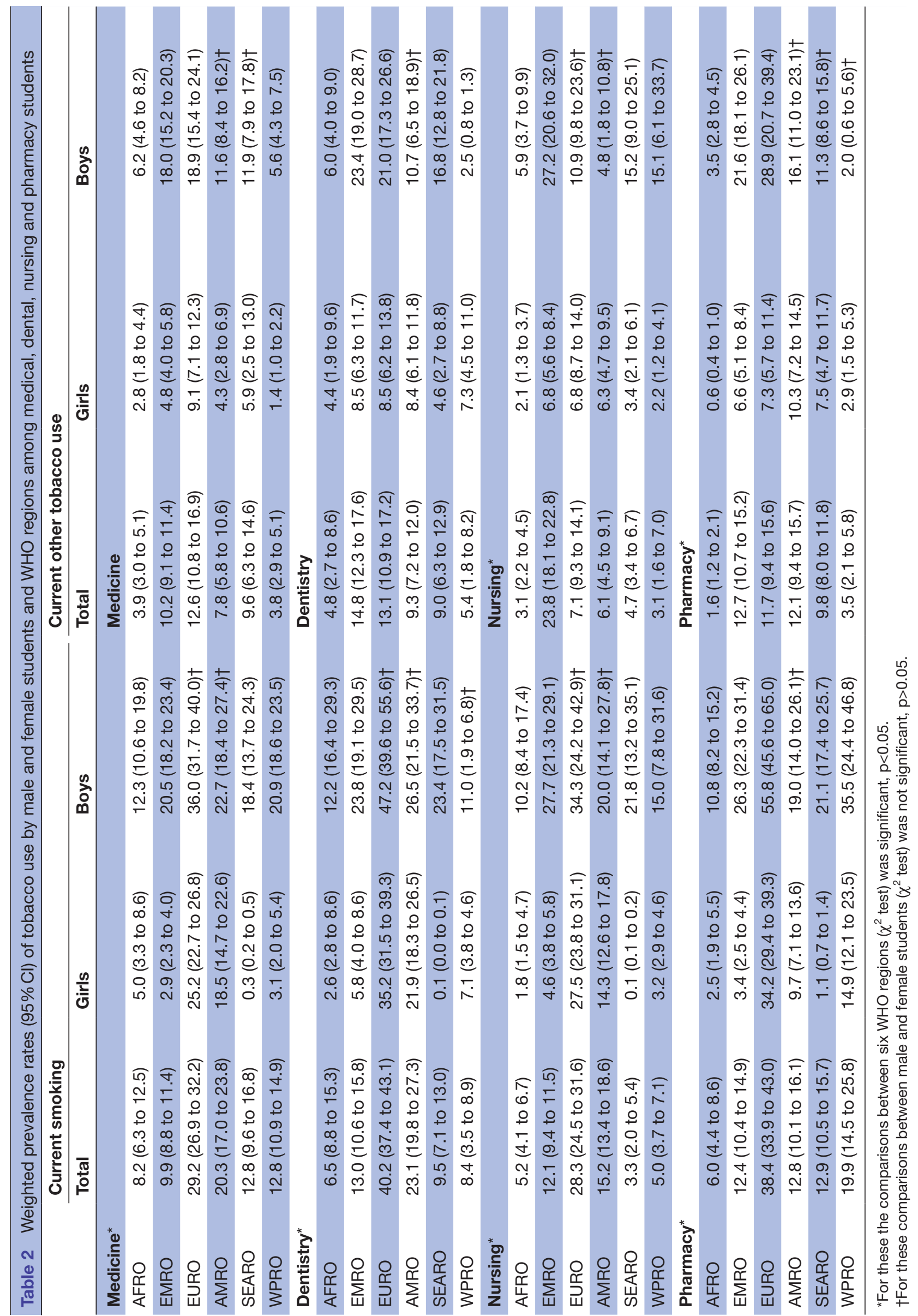




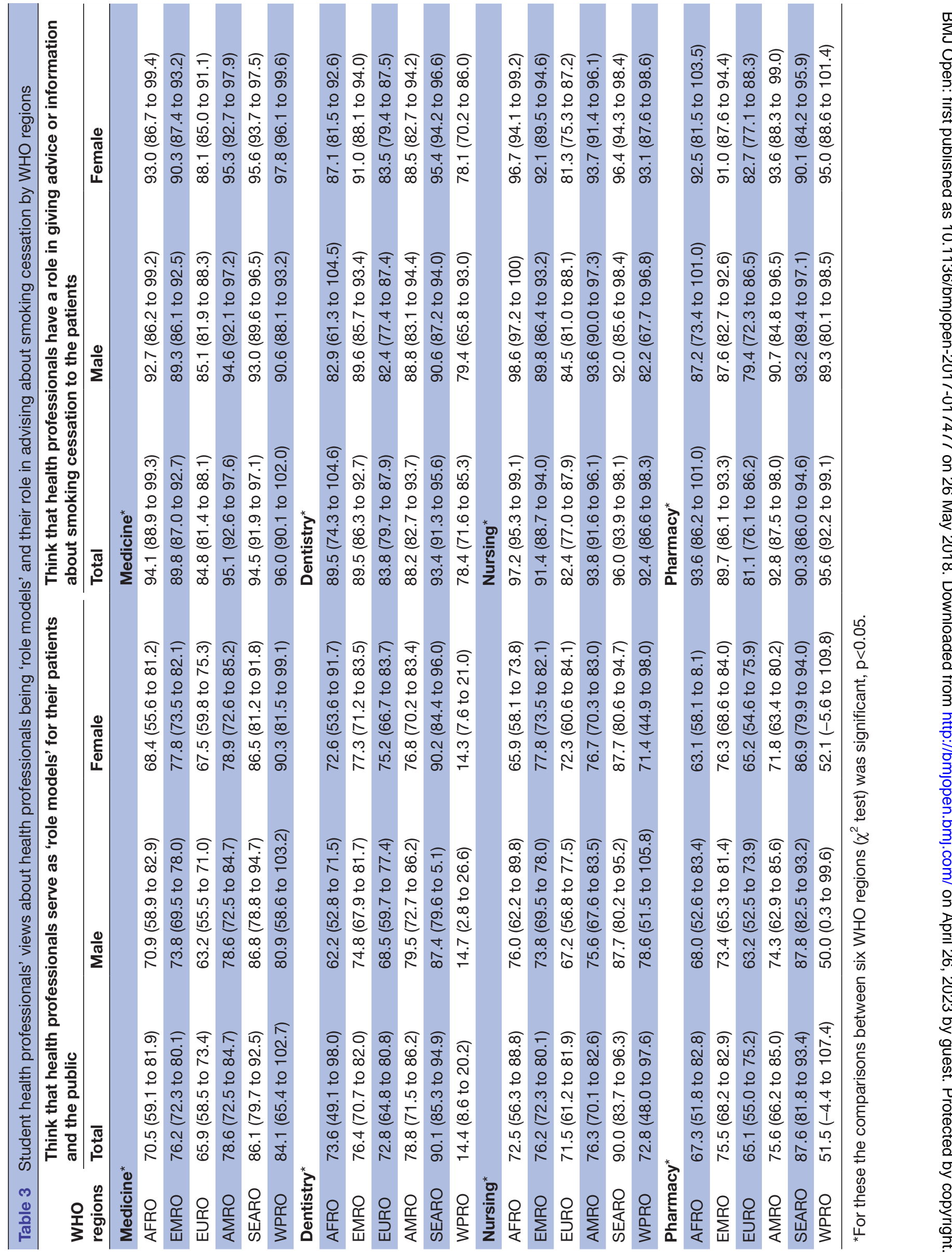




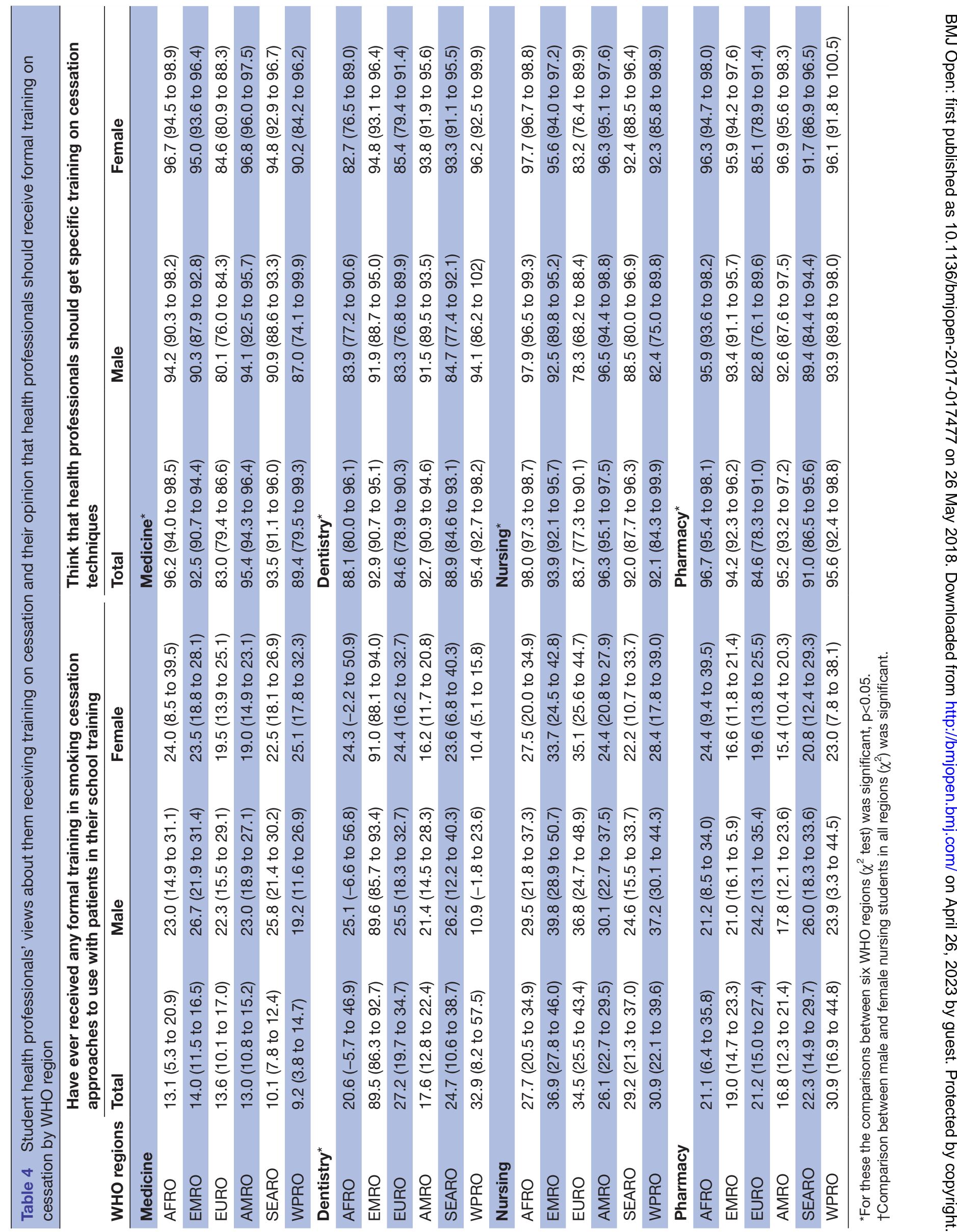


information about smoking cessation to their patients (table 3). In the countries surveyed in all the regions, the proportion of student health professionals who reported that they had received any formal training in smoking cessation approaches ranged from $9.2 \%$ to $36.9 \%$ only. However, $90 \%$ of dental students in the Eastern Mediterranean countries had received cessation training. More than $80 \%$ of all students of surveyed countries in all regions responded that student health professionals should receive specific training on cessation techniques. With the exception of cessation training among medical, nursing and pharmacy courses, all other indicators about the health professionals' role and cessation training in four disciplines were significantly different between the six WHO regions (table 4).

\section{DISCUSSION}

Tobacco use still being a major risk factor for non-communicable diseases, ${ }^{23}$ cessation training given for student health professionals remains inadequate, particularly in developing countries. ${ }^{31}{ }^{32}$ The aggregate tobacco use rates among health profession students varied by regions, disciplines and sex; cigarette smoking was higher among male students in dentistry and pharmacy particularly in the countries surveyed in Europe and the Americas. The results from all GHPSS throw light on two main shortcomings in health professionals' role in tobacco control. First, tobacco use among student health professionals themselves and second, a lack of formal cessation training in all disciplines, both of which affect their expected role in motivating their patients to quit smoking. On the contrary, students' perceptions towards cessation training were fairly consistent across the four disciplines and were favourable towards their role in cessation and receptive towards formal cessation training across surveyed countries in all the regions and in both sexes.

Smoking prevalence of up to $40 \%$ in the countries surveyed in Europe and the Americas (15\%-30\%) from GHPSS concur with reported smoking rates of $30 \%$ and higher among medical and dental students in central and eastern European countries. ${ }^{9} 10$ Most countries surveyed had smoking rates of over $20 \%$ reaching up to $60 \%$. However, the studies were not comparable due to heterogeneity in the definition of a 'smoker' and varying ( 1 week to 1 month) periods of recall ${ }^{910}$ used to define a 'smoker'. Such high rates correspond with the higher prevalence among men and women in the general population ${ }^{3}$ suggesting the influence of sociocultural factors. ${ }^{33}$ Lower smoking rates in Africa, South-East Asia and the Western Pacific region also correspond to lower adult smoking rates $^{3}$ particularly among women. In these regions, it is culturally inappropriate for women to smoke. ${ }^{34}$ Other tobacco use rates of up to $27 \%$ among male students in Eastern Mediterranean and European countries may be an influence of of 'Shisha' (water pipe) smoking prevalent in these regions. ${ }^{35}$
Smoking cessation should be prioritised for reducing the burden of smoking-related ill-health since quitting at any age confers health benefits. ${ }^{36}$ Nevertheless, prevalence of former smokers varies from $20 \%$ to $70 \%$, generally lower in developing countries where physicians seldom advice about quitting ${ }^{20}{ }^{31}$ despite the evidence that even a brief physician advice could have a small effect on smoking cessation. ${ }^{7}$ Reasons for patients who smoke not receiving any advice about quitting may arise from insufficient training, shortage of time and funding for physicians, and due to lack of policies for smoking cessation and poor infrastructure within the healthcare system. ${ }^{20}{ }^{31}$ Nurses and pharmacists too can play an important role in smoking cessation by counselling the patients who smoke. ${ }^{37} 38$ However, nursing curricula mainly cover the health hazards of smoking but not train students with the counselling skills, behavioural or pharmacotherapy for smoking cessation. ${ }^{39} 40$ In most GHPSS, research coordinators verified with school administrators and reconfirmed that there was no formal training given on tobacco cessation at any time during the course..$^{21}$

Tobacco control should begin with health professionals themselves being exemplars. Student health professionals surveyed in GHPSS generally agreed that health professionals should be 'role models' to their patients and acknowledged their role in advising patients on smoking cessation. ${ }^{41}$ Teachers of students health professionals should also advocate 'no tobacco' to their students by imparting education on health effects of smoking and motivating smoking students to quit their habit through counselling. ${ }^{32}$ More emphasis should be placed on student health professionals staying 'smoke-free' in European and American countries where smoking rates were higher. Exposure to SHS was high in educational institutions, ${ }^{22-24}$ hence, 'smoke-free' policies would create a positive message to the students, teachers, patients and doctors. ${ }^{42}$ Positive strides should be taken particularly in developing countries towards integrating tobacco cessation education into the existing curricula even if a separate module for tobacco control cannot be introduced. ${ }^{32}$ Health profession students can become exemplars by remaining non-smokers, if a positive and conducive environment can be generated by creating 'smoke-free' health profession schools and hospitals that provide cessation training. ${ }^{20}$

Our estimates expose wide gaps that exist globally in health professional students' preparation for their future role in smoking cessation. Most evaluation studies on various modalities of tobacco cessation training to improve students' skill to provide smoking cessation are from high-income countries, ${ }^{13-15} 4344$ where cessation training is implemented in the curriculum. ${ }^{31}$ However, very little is known about the effectiveness of cessation training materials and teaching methodologies in different socioeconomic and cultural settings of the low-and-middle-income countries (LMICs) of Africa and South-East Asia. ${ }^{14456}$ More research is needed to study the current curricula's content on tobacco cessation 
training in various courses, ${ }^{16}{ }^{47-49}$ student health professionals' current practices and attitudes, ${ }^{12}{ }^{17}$ 50-52 and medical educators' receptivity towards tobacco cessation. ${ }^{53}$ More recently different modalities of training medical students on smoking cessation training have been studied; yet, none provide any conclusive evidence on their effectiveness. ${ }^{54-56}$ Lack of time, poor long-term retention of counselling skills and lack of practice are reported as main barriers to implementation of tobacco cessation training. ${ }^{53}$ More research is needed to study the impact of the tobacco content in the present curriculum on future practice of health professionals. Research has shown that there are gaps in optometrists' training who also have a role in providing cessation advice to their patients. ${ }^{58} 59$ Future GHPPS should consider to include optometry students as well.

Our study limitations are: reporting bias of tobacco use; perceptions due to the questionnaire-based, self-reporting design of the GHPSS; and non-extrapolation of our results to the practising health professionals as described in previous papers. ${ }^{22-25}$ In addition, regional estimates may not be representative of some WHO regions, mainly Africa and the Western Pacific region, where very few countries were surveyed in the GHPSS. In the Western Pacific region, nursing and dental school surveys covered very few survey samples leading to inconsistent regional estimates from the meta-analyses. Further, in some countries, survey response rates were $<80 \%$ (table 1 ) which may not reflect the true estimates. Nevertheless, we presented regional estimates alongside country-wise updated results (online supplementary web appendix) to highlight the regional situation for policy makers.

\section{CONCLUSION}

Tobacco use among male medical and dental students are unacceptably high in Europe, America and the Eastern Mediterranean regions. Tobacco control efforts should begin with the student health professionals themselves abstaining from smoking to be exemplars to their patients and the public. Positive perceptions towards cessation training should be complimented by integration of cessation training into health professions' curricula. A collective effort by tobacco control experts and medical educators is needed to create a conducive and positive 'smoke free' school environment for training students in cessation techniques and further research should is needed for a better evidence base for the effectiveness of implementing tobacco-related curricula.

Contributors CTS and NR designed the study, with inputs from two other coauthors. IAM and MR managed data extraction, CTS analysed the data and IAM and MR interpreted the findings, with inputs from all other authors. CTS and NR co-drafted the manuscript, with critical feedback from IAM and MR. All authors approved the final manuscript.

Funding This research received no specific grant from any funding agency in the public, commercial or not-for-profit sectors.

Competing interests None declared.
Patient consent Not required.

Provenance and peer review Not commissioned; externally peer reviewed.

Data sharing statement Extra data can be accessed via the Dryad data repository at Dryad doi: 10.5061/dryad.5sq0q18.

Open Access This is an Open Access article distributed in accordance with the Creative Commons Attribution Non Commercial (CC BY-NC 4.0) license, which permits others to distribute, remix, adapt, build upon this work non-commercially, and license their derivative works on different terms, provided the original work is properly cited and the use is non-commercial. See: http://creativecommons.org/ licenses/by-nc/4.0/

(C) Article author(s) (or their employer(s) unless otherwise stated in the text of the article) 2018. All rights reserved. No commercial use is permitted unless otherwise expressly granted.

\section{REFERENCES}

1. World Health Organization. WHO global report on mortality attributable to tobacco, 2012. Geneva: World Health Organization, 2012.

2. Kassebaum NJ, Arora M, Barber RM, et al. Global, regional, and national disability-adjusted life-years (DALYs) for 315 diseases and injuries and healthy life expectancy (HALE), 1990-2015: a systematic analysis for the Global Burden of Disease Study 2015. Lancet 2016;388:1603-58.

3. Ng M, Freeman MK, Fleming TD, et al. Smoking prevalence and cigarette consumption in 187 countries, 1980-2012. JAMA 2014;311:183-92.

4. Bilano V, Gilmour S, Moffiet T, et al. Global trends and projections for tobacco use, 1990-2025: an analysis of smoking indicators from the WHO Comprehensive Information Systems for Tobacco Control. Lancet 2015;385:966-76.

5. Warren CW, Lee J, Lea V, et al. Evolution of the global tobacco surveillance system (GTSS) 1998-2008. Glob Health Promot 2009;16:4-37.

6. Carr AB, Ebbert J. Interventions for tobacco cessation in the dental setting. Cochrane Database Syst Rev 2012;6:CD005084.

7. Stead LF, Buitrago D, Preciado N, et al. Physician advice for smoking cessation. Cochrane Database Syst Rev 2013:CD000165.

8. World Health Organization. WHO framework convention on tobacco control. Geneva: World Health Organization, 2014.

9. Smith DR, Leggat PA. An international review of tobacco smoking among dental students in 19 countries. Int Dent J 2007:57:452-8.

10. Smith DR, Leggat PA. An international review of tobacco smoking among medical students. J Postgrad Med 2007;53:55-62.

11. La Torre G, Saulle R, Unim B, et al. Knowledge, attitudes, and smoking behaviours among physicians specializing in public health: a multicentre study. Biomed Res Int 2014;2014:516734.

12. Dania MG, Ozoh OB, Bandele EO. Smoking habits, awareness of risks, and attitude towards tobacco control policies among medical students in Lagos, Nigeria. Ann Afr Med 2015;14:1-7.

13. Sarna LP, Bialous SA, Kraliková E, et al. Impact of a smoking cessation educational program on nurses' interventions. J Nurs Scholarsh 2014;46:314-21.

14. Uti O, Sofola O. Impact of an educational intervention on smoking counseling practice among Nigerian dentists and dental students. Niger J Clin Pract 2015;18:75-9.

15. Wahl KR, Woolf BL, Hoch MA, et al. Promoting pharmacy-based referrals to the tobacco quitline: a pilot study of academic detailing administered by pharmacy students. J Pharm Pract 2015;28:162-5.

16. Richmond R, Zwar N, Taylor R, et al. Teaching about tobacco in medical schools: a worldwide study. Drug Alcohol Rev 2009;28:484-97.

17. Sreeramareddy CT, Suri S, Menezes RG, et al. Self-reported tobacco smoking practices among medical students and their perceptions towards training about tobacco smoking in medical curricula: A cross-sectional, questionnaire survey in Malaysia, India, Pakistan, Nepal, and Bangladesh. Subst Abuse Treat Prev Policy 2010;5:29.

18. Richmond $R$. The process of introducing a tobacco curriculum in medical school. Respirology 2004;9:165-72.

19. Thankappan KR, Yamini TR, Mini GK, et al. Assessing the readiness to integrate tobacco control in medical curriculum: experiences from five medical colleges in Southern India. Natl Med J India 2013;26:18-23.

20. Chatkin J, Chatkin G. Learning about smoking during medical school: are we still missing opportunities? Int J Tuberc Lung Dis 2009;13:429-37. 
21. Warren CW, Jones NR, Chauvin J, et al. Tobacco use and cessation counselling: cross-country. Data from the Global Health Professions Student Survey (GHPSS), 2005-7. Tob Control 2008;17:238-47.

22. Warren CW, Sinha DN, Lee J, et al. Tobacco use, exposure to secondhand smoke, and cessation counseling among medical students: cross-country data from the Global Health Professions Student Survey (GHPSS), 2005-2008. BMC Public Health 2011;11:72

23. Warren CW, Sinha DN, Lee J, et al. Tobacco use, exposure to secondhand smoke, and cessation counseling training of dental students around the world. J Dent Educ 2011;75:385-405.

24. Warren CW, Sinha DN, Lee J, et al. Tobacco use, exposure to secondhand smoke, and training on cessation counseling among nursing students: cross-country data from the Global Health Professions Student Survey (GHPSS), 2005-2009. Int J Environ Res Public Health 2009;6:2534-49.

25. Warren C, Sinha D, Lee J, et al. Tobacco use and cessation counseling among pharmacy students. J Behavior Health 2013;2:8-18.

26. Richmond R, Taylor R. Global dissemination of a tobacco curriculum in medical schools. Int J Tuberc Lung Dis 2006;10:750-5.

27. Richmond R. Education and training for health professionals and students in tobacco, alcohol and other drugs. Drug Alcohol Rev 2009;28:463-5.

28. Gualano MR, Bontempi C, Saulle R, et al. Validation of the global health professions students survey questionnaire in Italy. Italian $J$ Public Health 2012;8.

29. Centers for Disease Control and Prevention (CDC). Tobacco use and cessation counseling-global health professionals survey pilot study, 10 countries, 2005. MMWR Morb Mortal Wkly Rep 2005;54:505-9.

30. Nyaga VN, Arbyn M, Aerts M. Metaprop: a Stata command to perform meta-analysis of binomial data. Arch Public Health 2014;72:39.

31. Abdullah AS, Husten CG. Promotion of smoking cessation in developing countries: a framework for urgent public health interventions. Thorax 2004;59:623-30.

32. Muramoto ML, Lando $\mathrm{H}$. Faculty development in tobacco cessation: training health professionals and promoting tobacco control in developing countries. Drug Alcohol Rev 2009;28:498-506.

33. Bobo JK, Husten C. Sociocultural influences on smoking and drinking. Alcohol Res Health 2000;24:225-32.

34. Mackay J, Amos A. Women and tobacco. Respirology 2003;8:123-30.

35. Eriksen M, Mackay J, Ross H. The tobacco atlas. US: American Cancer Society, 2013

36. Ezzati M, Lopez AD. Estimates of global mortality attributable to smoking in 2000. Lancet 2003;362:847-52.

37. Rice VH, Hartmann-Boyce J, Stead LF. Nursing interventions for smoking cessation. Cochrane Database Syst Rev 2013:CD001188.

38. Sinclair HK, Bond CM, Lennox AS, et al. Training pharmacists and pharmacy assistants in the stage-of-change model of smoking cessation: a randomised controlled trial in Scotland. Tob Control 1998;7:253-61.

39. Chan SS, Sarna L, Danao LL. Are nurses prepared to curb the tobacco epidemic in China? A questionnaire survey of schools of nursing. Int J Nurs Stud 2008;45:706-13.
40. Sarna L, Danao LL, Chan SS, et al. Tobacco control curricula content in baccalaureate nursing programs in four Asian nations. Nurs Outlook 2006;54:334-44.

41. Maeckelberghe EL. Doctors and medical students as non-smoking role models? Using the right arguments. Eur J Public Health 2013;23:190-2.

42. Fichtenberg CM, Glantz SA. Effect of smoke-free workplaces on smoking behaviour: systematic review. BMJ 2002;325:188.

43. Singleton JA, Carrico RM, Myers JA, et al. Tobacco cessation treatment education for dental students using standardized patients. $J$ Dent Educ 2014;78:895-905.

44. Saba M, Bittoun R, Saini B. A workshop on smoking cessation for pharmacy students. Am J Pharm Educ 2013;77:198.

45. Tao S, Croucher R, Pau A. Impact of the curriculum on Chinese dental students' tobacco control attitudes and beliefs: a case study in Harbin, China. Int Dent J 2008;58:181-6.

46. Fotedar S, Sogi GM, Fotedar V, et al. Knowledge of, attitude towards, and prevalence of tobacco use among dental students in Himachal Pradesh State, India. Oral Health Dent Manag 2013;12:73-9.

47. Leong SL, Lewis PR, Curry WJ, et al. Tobacco world: evaluation of a tobacco cessation training program for third-year medical students. Acad Med 2008;83:S25-S28.

48. Pizzo G, Davis JM, Licata ME, et al. Assessment of tobacco dependence curricula in Italian dental hygiene schools. J Dent Educ 2013;77:1072-8.

49. Dable RA, Wasnik PB, Pawar BR, et al. Assessment of professional competency and need of smoking cessation counseling for dental students. J Educ Eval Health Prof 2014;11:26.

50. Chan SS, Sarna L, Wong DC, et al. Nurses' tobacco-related knowledge, attitudes, and practice in four major cities in China. $J$ Nurs Scholarsh 2007;39:46-53.

51. Geller AC, Brooks DR, Powers CA, et al. Tobacco cessation and prevention practices reported by second and fourth year students at US medical schools. J Gen Intern Med 2008;23:1071-6.

52. Kusma B, Quarcoo D, Vitzthum K, et al. Berlin's medical students' smoking habits, knowledge about smoking and attitudes toward smoking cessation counseling. J Occup Med Toxicol 2010;5:9.

53. Lenz BK. Faculty-perceived barriers and benefits to teaching tobacco cessation. Nurs Educ Perspect 2013;34:178-81.

54. Herold R, Schiekirka S, Brown J, et al. Structured smoking cessation training for medical students: a prospective study. Nicotine Tob Res 2016:18:2209-15.

55. Ockene JK, Hayes RB, Churchill LC, et al. Teaching medical students to help patients quit smoking: outcomes of a 10-school randomized controlled trial. J Gen Intern Med 2016;31:172-81.

56. Stolz D, Langewitz W, Meyer A, et al. Enhanced didactic methods of smoking cessation training for medical students-a randomized study. Nicotine Tob Res 2012;14:224-8.

57. Zwar NA, Richmond RL, Davidson D, et al. Postgraduate education for doctors in smoking cessation. Drug Alcohol Rev 2009;28:466-73.

58. Lorencatto F, Harper AM, Francis JJ, et al. A survey of UK optometry trainees' smoking cessation training. Ophthalmic Physiol Opt 2016;36:494-502.

59. Lawrenson JG, Roberts CA, Offord L. A pilot study of the feasibility of delivering a brief smoking cessation intervention in community optometric practice. Public Health 2015;129:149-51. 